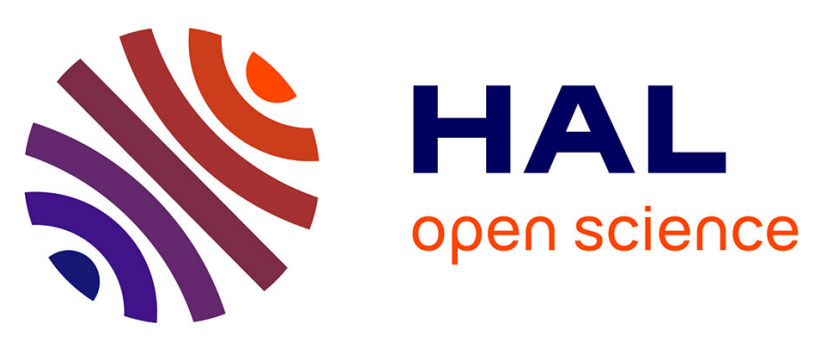

\title{
Systemic air embolism depicted on systematic whole thoracic CT acquisition after percutaneous lung biopsy: Incidence and risk factors
}

\author{
Valérie Monnin-Bares, Guillaume Chassagnon, Hélène Vernhet-Kovacsik, \\ Hamid Zarqane, Juliette Vanoverschelde, Marie Christine Picot, Sebastien \\ Bommart
}

\section{To cite this version:}

Valérie Monnin-Bares, Guillaume Chassagnon, Hélène Vernhet-Kovacsik, Hamid Zarqane, Juliette Vanoverschelde, et al.. Systemic air embolism depicted on systematic whole thoracic CT acquisition after percutaneous lung biopsy: Incidence and risk factors. European Journal of Radiology, 2019, 117, pp.26-32. 10.1016/j.ejrad.2019.05.016 . hal-02302626

\section{HAL Id: hal-02302626 \\ https://hal.science/hal-02302626}

Submitted on 16 Jun 2020

HAL is a multi-disciplinary open access archive for the deposit and dissemination of scientific research documents, whether they are published or not. The documents may come from teaching and research institutions in France or abroad, or from public or private research centers.
L'archive ouverte pluridisciplinaire HAL, est destinée au dépôt et à la diffusion de documents scientifiques de niveau recherche, publiés ou non, émanant des établissements d'enseignement et de recherche français ou étrangers, des laboratoires publics ou privés. 


\title{
Systemic air embolism depicted on systematic whole thoracic CT acquisition after percutaneous lung biopsy: Incidence and risk factors
}

\author{
Valérie Monnin-Bares $^{\mathrm{a}, *}$, Guillaume Chassagnon ${ }^{\mathrm{b}}$, Hélène Vernhet-Kovacsik ${ }^{\mathrm{a}}$, Hamid Zarqane ${ }^{\mathrm{a}}$, \\ Juliette Vanoverschelde ${ }^{\mathrm{a}}$, Marie Christine Picot $^{\mathrm{c}}$, Sébastien Bommart ${ }^{\mathrm{a}, \mathrm{c}}$ \\ ${ }^{a}$ Radiology Department, CHRU Montpellier, France \\ ${ }^{\mathrm{b}}$ Radiology Department, Groupe Hospitalier Cochin-Hotel Dieu, AP-HP, Université Paris-Descartes, Paris, France \\ ${ }^{\mathrm{c}}$ PhyMedExp, University of Montpellier, INSERM U1046, CNRS UMR 9214, Montpellier, France
}

\section{Keywords:}

Embolism, air

Image-guided biopsy

Tomography, X-Ray computed

Radiology

Interventional

Risk factors

\begin{abstract}
A B S T R A C T
Objectives: To evaluate the incidence and risk factors of systemic air embolism (SAE) depicted on systematic whole thoracic CT performed after percutaneous lung biopsy.

Methods: A total of 559 CT-guided lung biopsies performed between April 2014 and May 2016 were retrospectively evaluated. SAE was defined by the presence of air in the aorta or left cardiac cavities seen on whole thorax CT images acquired after needle withdrawal. Analyzed data focused on patient (age, sex, spirometry data, emphysema on CT, therapeutics received), target lesion (location, depth, size and feature) and procedure (patient position, length of intrapulmonary needle path, number of pleural passes and of biopsy samples, operator's experience). A regression logistic model was used to identify risk factors of SAE.

Results: SAE was observed after 27 of the 559 lung biopsies, corresponding to a radiological incidence of $4.8 \%$ (95\%CI: 3.3-7.0). Clinical incidence was $0.17 \%(n=1)$. For $21 / 27$ patients $(78 \%)$, a targeted acquisition in the nodule area would not have included the cardiac cavities meaning SAE would have been missed. On multivariate analysis, the independent risk factors were needle path length through ventilated lung (OR: 1.13 , 95\%CI: 1.02-1.25, $\mathrm{p}=0.024$ ), number of samples (OR: $1.48,95 \% \mathrm{CI}: 1.01-2.17, \mathrm{p}=0.046)$ and prone position (OR: 3.12, 95\%CI: 1.11-8.31, $\mathrm{p}=0.031$ ) or right-sided lateral decubitus (OR: 6.15, 95\%CI: $1.66-22.85, \mathrm{p}=0.005$ ). Conclusions: Asymptomatic systemic air embolism can be depicted in almost 5\% of post biopsy CT examinations, when they are not limited to the targeted nodule area but include the entire thorax.
\end{abstract}

\section{Introduction}

The air inlet into a pulmonary vein secondary to a percutaneous CTguided lung biopsy can be expelled into the systemic circulation, leading to a systemic air embolism (SAE).

SAE is traditionally considered as an extremely rare complication of percutaneous lung biopsy, according to two large series that reported an incidence of 0.02 [1] and $0.07 \%$ [2]. Current literature mainly includes case reports or small case series of SAE. The majority of published cases report cardiac and/or neurological symptoms, frequently with a fatal evolution, especially if diagnosis has been delayed [3-11]. However, its incidence might be underestimated in cases where SAE is not associated with clinical symptoms. In 2007, Hiraki [7] was the first author to describe SAE in asymptomatic patients and to emphasize the necessity of a post-procedural CT scanning performed through the whole thorax, in order to depict systemic air embolism. Immediate recognition of SAE has been reported as the main factor to minimize severe complications since specific management of patient can be initiated earlier $[7,12,13]$.

The purpose of this study was to retrospectively assess the incidence of systemic air embolism depicted on whole chest CT acquisition, systematically performed after percutaneous lung biopsy, in a large cohort of consecutive patients. The secondary objective was to determine risk factors for this complication.

\section{Materials and methods}

\subsection{Patients}

This retrospective cohort study received the approval of the local

\footnotetext{
Abbreviations: CT, computed tomography; CI, confidence interval; OR, odds ratio; SAE, Systemic air embolism; RLD, right lateral decubitus *Corresponding author at: Radiology Department, CHRU Arnaud de Villeneuve, 371 avenue du Doyen Gaston Giraud, 34295, Montpellier, Cedex 5, France. E-mail address: v-monnin@chu-montpellier.fr (V. Monnin-Bares).
} 
Table 1

Global population's characteristics and results of univariate analysis for risk factors of air embolism.

\begin{tabular}{|c|c|c|c|c|}
\hline Characteristics & $\begin{array}{l}\text { Global } \\
\text { population } \\
\mathrm{N}=559\end{array}$ & $\begin{array}{l}\text { No air } \\
\text { embolism } \\
N=532\end{array}$ & $\begin{array}{l}\text { Air } \\
\text { embolism } \\
\mathrm{N}=27\end{array}$ & $P$ value \\
\hline Age (y) median $\left(Q_{25}-Q_{75}\right)$ & $65(59-73)$ & $65(59-73)$ & $669(61-78)$ & 0.11 \\
\hline Gender n (\%) & & & & 0.83 \\
\hline Male & $363(64.9)$ & $346(65.0)$ & $17(63.0)$ & \\
\hline Female & $196(35.1)$ & $186(35.0)$ & $7(26.0)$ & \\
\hline Emphysema & & & & 0.66 \\
\hline Yes & $226(40.4)$ & $214(40.2)$ & $12(44.4)$ & \\
\hline No & $333(59.6)$ & $318(59.8)$ & $15(55.6)$ & \\
\hline Spirometry data n (\%) & & & & 0.08 \\
\hline Normal & $347(62.4)$ & $335(63.3)$ & $12(44.4)$ & \\
\hline Obstructive pattern & $186(33.5)$ & $173(32.7)$ & $13(48.2)$ & \\
\hline Restrictive pattern & $23(4.1)$ & $21(4.0)$ & $2(7.4)$ & \\
\hline \multicolumn{5}{|l|}{ Prior treatments } \\
\hline $\begin{array}{l}\text { Ipsilateral surgery or } \\
\text { contralateral } \\
\text { pneumonectomy }\end{array}$ & & & & 0.38 \\
\hline Yes & $27(4.8 \%)$ & $25(4.7 \%)$ & $2(7.4 \%)$ & \\
\hline No & $532(95.2 \%)$ & $507(95.3 \%)$ & $25(92.6 \%)$ & \\
\hline Ipsilateral radiotherapy & & & & 0.16 \\
\hline Yes & $15(2.7 \%)$ & $13(2.4 \%)$ & $2(7.4 \%)$ & \\
\hline No & $544(97.3 \%)$ & $519(97.6 \%)$ & $25(92.6 \%)$ & \\
\hline Vasculitis & & & & 0.472 \\
\hline Yes & $10(1.8 \%)$ & $10(1.9 \%)$ & $0(0 \%)$ & \\
\hline No & $549(98.2 \%$ & $522(98.1 \%)$ & $27(100 \%)$ & \\
\hline
\end{tabular}

Research Ethics Committee of our institution (2017_CLER-MPT_10-05), which waived the need for patient consent.

All thoracic biopsies consecutively performed between April 2014 and May 2016 at our department were included, after query in our local thoracic biopsy database. Biopsies had been scheduled after the weekly thoracic oncology multidisciplinary team meeting. Among the 587 procedures, 28 patients presenting pleural $(n=13)$, chest wall $(n=6)$ or mediastinal lesions $(n=9)$ were excluded due to the absence of intra-parenchymal needle path. The final cohort was composed of 559 patients; their characteristics are presented in Table 1.

\subsection{Biopsy procedure}

All biopsy procedures were performed by five staff radiologists, with 2-11 years of experience. The biopsies were performed under local anesthesia except for three patients who required general anesthesia on their personal request.

Blood pressure, heart rate, ECG and blood oxygen saturation were monitored throughout the entire procedure.

Patient position was determined by the radiologist, in order to select the safest access route to the lesion with regard to the shortest needle track through the lung, avoiding fissure, large vessel or bullae.

CT guidance was performed using a 64-multidetector CT scan (VCT LightSpeed 64, GE Healthcare, Milwaukee, Wis) until October 2015 (412 patients) or a 256-slices CT system (Revolution CT, GE Healthcare) from November 2015 (147 patients). Repeated unenhanced axial CT images were acquired over a limited length, with a $2.5-\mathrm{mm}$ slice thickness using the 64-slice unit and 1.25-mm using the Revolution CT) for planning and monitoring the needle path. After local anesthesia, a 17-gauge coaxial needle (Co-Axial Introducer Needle; Argon Medical Device; USA) was gradually inserted to reach the target lesion, according to current guidelines [14]. When the coaxial needle was in position, the internal stylet was removed and a 18-gauge core biopsy needle (BioPince Full Core Biopsy instrument; Argon Medical Device; USA) was immediately placed. The needle guide hub was occluded with a finger during each transition between the stylet and the biopsy needle. During this process, patients were instructed to breathe as gently as possible or hold their breath according to their capabilities.

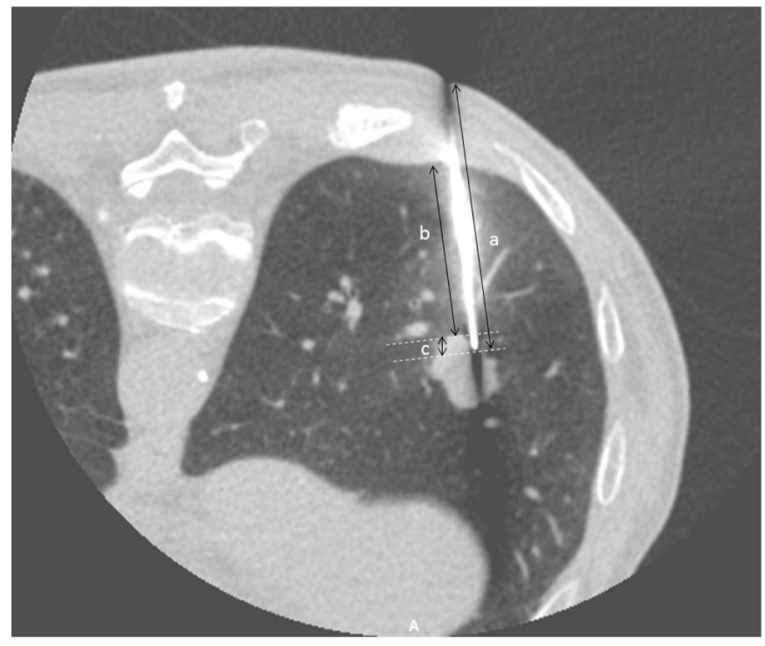

Fig. 1. Different lengths of the needle trajectory. (a)Total intra pulmonary path. (b)Needle path through ventilated lung. (c)Needle penetration depth in the tumour.

The notch length $(13,23$ or $33 \mathrm{~mm})$ was set depending on the target lesion size. Two or more samples were obtained for pathologic examination.

After the coaxial needle withdrawal, a CT acquisition of the whole thorax was performed with the patient remaining in the same position, in order to detect procedure-related complications.

\subsection{Retrospective reading}

A retrospective reading on PACS workstation (Advantage Window 7.7 GE Healthcare) was performed for all procedures by a chest radiologist with 7 years of experience (VMB).

The target lesion characteristics were analyzed, including its greater axial diameter, its density and feature (cavitary or not), its location (subpleural, intrapulmonary or paramediastinal, upper and middle lobes or lower lobe location, position relative to the left atrium center and depth, defined as the shortest length from the peripheral pleura to the nodule).

The presence or absence of emphysema on CT was also noted.

Procedure characteristics included the patient positioning, the needle path length (Fig. 1) and the number of pleural passes (1 or $>1)$. The notch length and the number of biopsy samples were retrieved from the procedure report.

SAE was defined as the presence of air in the left cardiac cavities or the aorta, visible on at least two consecutive slices, that was not present on the pre-therapeutic CT. If air bubbles were already present in the right cavities on the CT images performed prior to the biopsy, in connection with a purge defect during the placement of the peripheral venous pathway, these patients were not considered as part of "air embolism group".

Incidence of air embolism was also evaluated for each operator.

Procedure characteristics are summarized in Table 2.

\subsection{Patient characteristics}

Electronic medical records were used to collect the following information: age, gender, spirometry data (normal, obstructive or restrictive pattern), prior therapeutics received (ipsilateral surgery or contralateral pneumonectomy, ipsilateral radiotherapy) and context or not of vasculitis.

Patient characteristics are summarized in Table 1. 
Table 2

Target lesion and procedure data and results of univariate analysis for risk factors of air embolism.

\begin{tabular}{|c|c|c|c|c|}
\hline Data & $\begin{array}{l}\text { Global } \\
\text { population } \\
\mathrm{N}=559\end{array}$ & $\begin{array}{l}\text { No air } \\
\text { embolism } \\
\mathrm{N}=532\end{array}$ & $\begin{array}{l}\text { Air } \\
\text { embolism } \\
\mathrm{N}=27\end{array}$ & $P$ value \\
\hline $\begin{array}{l}\text { Nodule size }(\mathrm{mm}) \\
\quad \text { median }\left(\mathrm{Q}_{25}-\mathrm{Q}_{75}\right)\end{array}$ & $21(13-42)$ & $21(13-43)$ & $18(14-33)$ & 0.77 \\
\hline Nodule feature n (\%) & & & & 0.25 \\
\hline Solid & $455(81.3)$ & $435(81.8)$ & $20(74.1)$ & \\
\hline Partially solid & $34(6.1)$ & $30(6)$ & $4(14.8)$ & \\
\hline Ground glass & $22(3.9)$ & $21(4)$ & $1(3.7)$ & \\
\hline Cavitary & $48(8.6)$ & $46(8.6)$ & $2(7.4)$ & \\
\hline \multicolumn{5}{|l|}{ Lesion location $\mathrm{n}(\%)$} \\
\hline Lobar location & & & & 0.26 \\
\hline Upper and middle lobes & $347(62.1)$ & $333(62.6)$ & $14(51.9)$ & \\
\hline Lower lobe & $212(37.9)$ & $199(37.4)$ & $13(48.1)$ & \\
\hline Topography & & & & 0.14 \\
\hline Sub pleural & $242(43.3)$ & $234(44.0)$ & $8(29.6)$ & \\
\hline $\begin{array}{l}\text { Intrapulmonary or } \\
\text { paramediastinal }\end{array}$ & $317(56.1)$ & $298(56.0)$ & $19(70.4)$ & \\
\hline $\begin{array}{l}\text { Location above the level } \\
\text { of left atrium }\end{array}$ & $435(77.8)$ & $413(77.6)$ & $22(81.5)$ & 0.64 \\
\hline $\begin{array}{l}\text { Depth }(\mathrm{mm}) \text { median } \\
\quad\left(\mathrm{Q}_{25}-\mathrm{Q}_{75}\right)\end{array}$ & $7(0-17)$ & $7(0-17)$ & $13(0.22)$ & 0.07 \\
\hline Position n (\%) & & & & 0.03 \\
\hline Right lateral decubitus & $47(8.4)$ & $42(7.9)$ & $5(18.5)$ & \\
\hline Prone & $276(49.4)$ & $259(48.7)$ & $17(63.0)$ & \\
\hline Supine & $195(34.9)$ & $190(35.7)$ & $5(18.5)$ & \\
\hline Left lateral decubitus & $41(7.3)$ & $41(7.7)$ & $0(0.0)$ & \\
\hline \multicolumn{5}{|l|}{$\begin{array}{l}\text { Length of the needle } \\
\text { trajectory }(\mathrm{mm}) \\
\text { median }\left(\mathrm{Q}_{25}-\mathrm{Q}_{75}\right)\end{array}$} \\
\hline $\begin{array}{l}\text { Total intrapulmonary } \\
\text { path }\end{array}$ & $19(10-33)$ & $19(19-32)$ & $28(17-39)$ & 0.03 \\
\hline $\begin{array}{c}\text { Needle path through } \\
\text { ventilated lung }\end{array}$ & $14(0-30)$ & $13(0-30)$ & $25(15-36)$ & 0.04 \\
\hline $\begin{array}{l}\text { Needle penetration } \\
\text { depth in the tumour }\end{array}$ & $2(0-7)$ & $2(0-7)$ & $3(0-8)$ & 0.71 \\
\hline $\begin{array}{l}\text { Location of the needle } \\
\text { tip to the lesion }\end{array}$ & & & & 0.96 \\
\hline Outside & $184(32.9)$ & $175(32.9)$ & $9(33.3)$ & \\
\hline Inside & $375(67.1)$ & $357(67.1)$ & $18(67.7)$ & \\
\hline $\begin{array}{l}\text { Number of pleural } \\
\text { passes }>1 \mathrm{n}(\%)\end{array}$ & $117(20.9)$ & $108(20.3)$ & $9(33.3)$ & 0.10 \\
\hline $\begin{array}{l}\text { Number of biopsy } \\
\quad \text { samples } \\
\text { median }\left(\mathrm{Q}_{25}-\mathrm{Q}_{75}\right) \\
\text { Notch length } \mathrm{n}(\%)\end{array}$ & $3(2-3)$ & $3(2-3)$ & $3(2-4)$ & 0.03 \\
\hline $13 \mathrm{~mm}$ & $458(82.2)$ & $437(82.5)$ & $21(77.8)$ & 0.63 \\
\hline $23 \mathrm{~mm}$ & $90(16.2)$ & 84 (15.9) & $6(22.2)$ & \\
\hline $33 \mathrm{~mm}$ & $9(1.6)$ & $9(1.7)$ & $0(0.0)$ & \\
\hline \multicolumn{5}{|l|}{$\begin{array}{l}\text { Post procedure } \\
\text { complications } n\end{array}$} \\
\hline Pneumothorax & $58(10.4)$ & $54(10.2 \%)$ & $4(14.8)$ & 0.51 \\
\hline Hemoptysis & $35(6.3)$ & $35(6.6)$ & $0(0.0)$ & 0.17 \\
\hline Alveolar opacities & $171(30.6)$ & $161(30.3)$ & $10(37.0)$ & 0.46 \\
\hline
\end{tabular}

\subsection{Other complications}

The occurrence of other complications such as pneumothorax, intra alveolar hemorrhage and hemoptysis was also analyzed.

\subsection{Statistical analysis}

Patients' characteristics are presented using median and interquartile range $\left(Q_{25}-Q_{75}\right)$ for continuous variables and frequencies with proportions for categorical variables. The characteristics of the 2 groups, with and without SAE, were compared using Wilcoxon rank test for continuous variables and Chi-square or Fisher test for categorical ones. Multivariate logistic regression was performed to identify risk factors for SAE. The dependent variables were included in the model according to significance level or clinical coherence. A backward selection was used; the $\alpha$-to-enter and the $\alpha$-to-exit were set, respectively, at 0.20 and 0.10 . Missing data have not been replaced. Statistical bilateral significance threshold was set at $5 \%$. Analyses were performed using SAS version 9.1 (SAS Institute, Cary, North Carolina).

\section{Results}

\subsection{Radiological and clinical features of air embolism}

Whole thoracic CT acquisition after needle withdrawal, revealed SAE in 27 of the 559 patients included (4.8\% [95\%CI: 3.3-7.0]).

Air was detected in the left atrium for thirteen patients (48\%), in the left ventricle for nine (33\%), both in the left atrium and the left ventricle for four and in the descending aorta for one.

For $21 / 27$ patients $(78 \%)$, the nodule area was outside the level of the cardiac cavities, meaning that a targeted post procedural CT acquisition limited to the nodule area would have missed the SAE.

The biopsy had been performed under general anesthesia in 3 cases including one of the 27 patients with SAE.

The incidence of SAE was not different according to the operator, respectively of $4.8 \%, 3.9 \%, 3.5 \%, 5.6 \%$ and $3.8 \%(\mathrm{p}=0.98)$, even for younger less experienced operators.

All SAE had been detected by the operator on the last whole thoracic CT acquisition, allowing adapted management.

All but one were asymptomatic, so the clinical incidence was $0.17 \%$. The symptomatic patient was in prone position during the biopsy. At the end of the procedure, after the last CT acquisition, the patient moved his arm for a more comfortable position while the radiologist was reading the CT images showing SAE in the left cardiac cavities (Fig. 2). The patient experienced a sudden chest pain, with no ST change on ECG monitoring, and developed a right hemiplegia. He was immediately administered $100 \%$ oxygen through a mask and mobilization was prohibited. On the control CT performed 4 min later, a complete resorption of air was observed. A brain CT scan was performed and did not depict cerebral air embolism. Hyperbaric oxygen therapy was performed at $3 \mathrm{~atm}$ absolute with $100 \%$ oxygen for $90 \mathrm{~min}$, allowing right hemiplegia resolution. The patient was discharged after one night of hospitalization.

The twenty-six other patients were asymptomatic. Their management included initiation of $100 \%$ mask oxygen therapy, monitoring of cardiac and respiratory parameters, prohibition of position changes and repeated CT scans until air collection disappearance. All were discharged on the same day of procedure except four patients who required chest tube placement for associated pneumothorax.

\subsection{Risk factors for $S A E$}

Tables 1 and 2 summarize the results of univariate analysis comparing patients who presented air embolism $(n=27)$ and those who did not $(n=532)$. The position of the patient (prone and right lateral decubitus), the number of biopsy samples and the needle path length through lung parenchyma differ significantly between the 2 groups. No significant differences were observed for nodule size or nodule feature. Only 2 of the 48 cavitary lesion biopsies were complicated by SAE. Neither the lobar location nor the position of the target above the level of the left atrium influenced the occurrence of SAE. The notch length did not significantly differ between the 2 groups. No significant differences were observed in prior treatment between the two groups even if $7.4 \%$ of patients with SAE had a prior ipsilateral radiotherapy versus only $2.4 \%$ of control group. Only 10 patients had vasculitis but none of them presented air embolism.

The following variables were included in the multivariate model: age, prior ipsilateral radiotherapy, length of needle path through ventilated lung, number of biopsy samples number of pleural passes $>1$, position, spirometry data and emphysema. Depth, length of intrapulmonary path and location of lesion were not introduced in the 


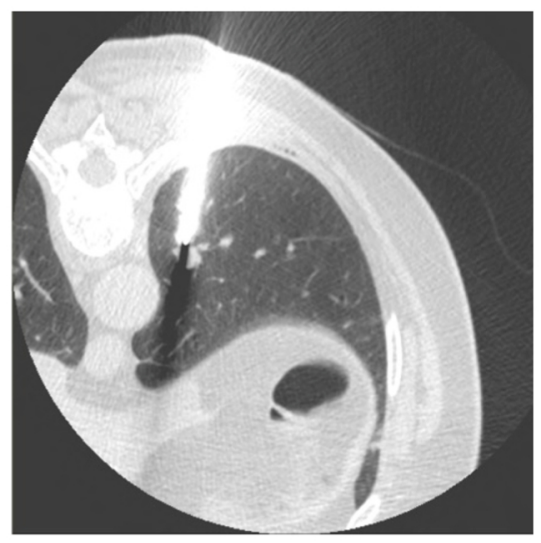

a.
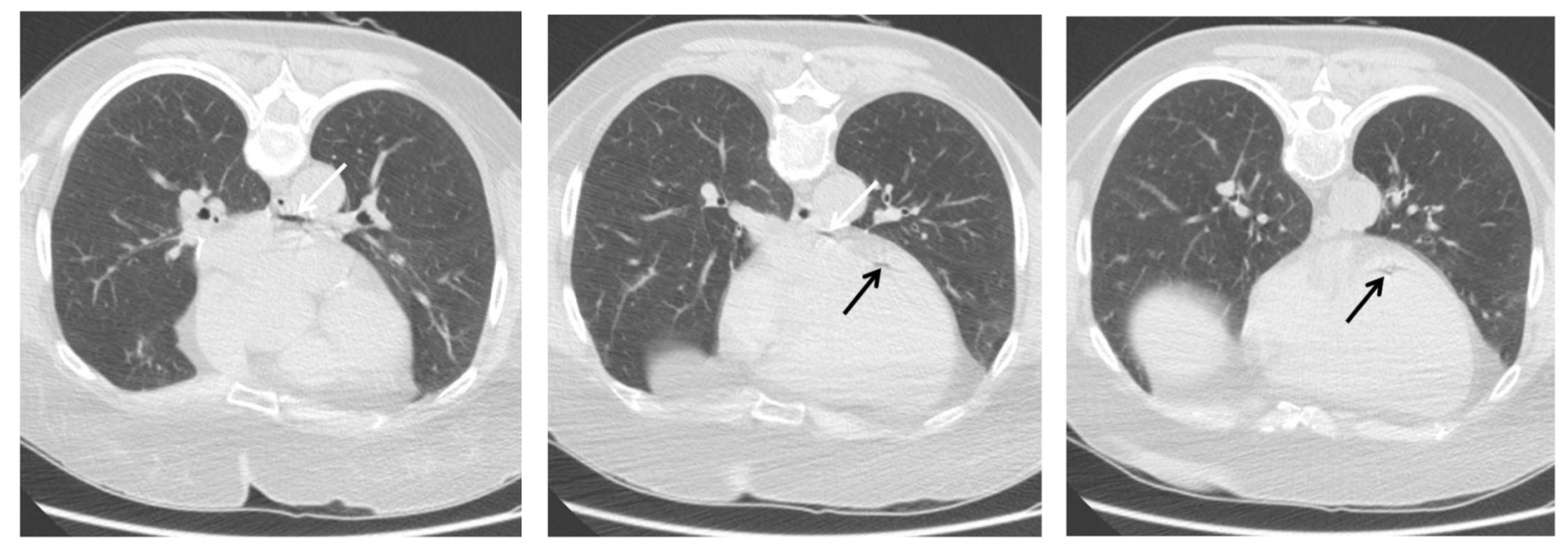

b.
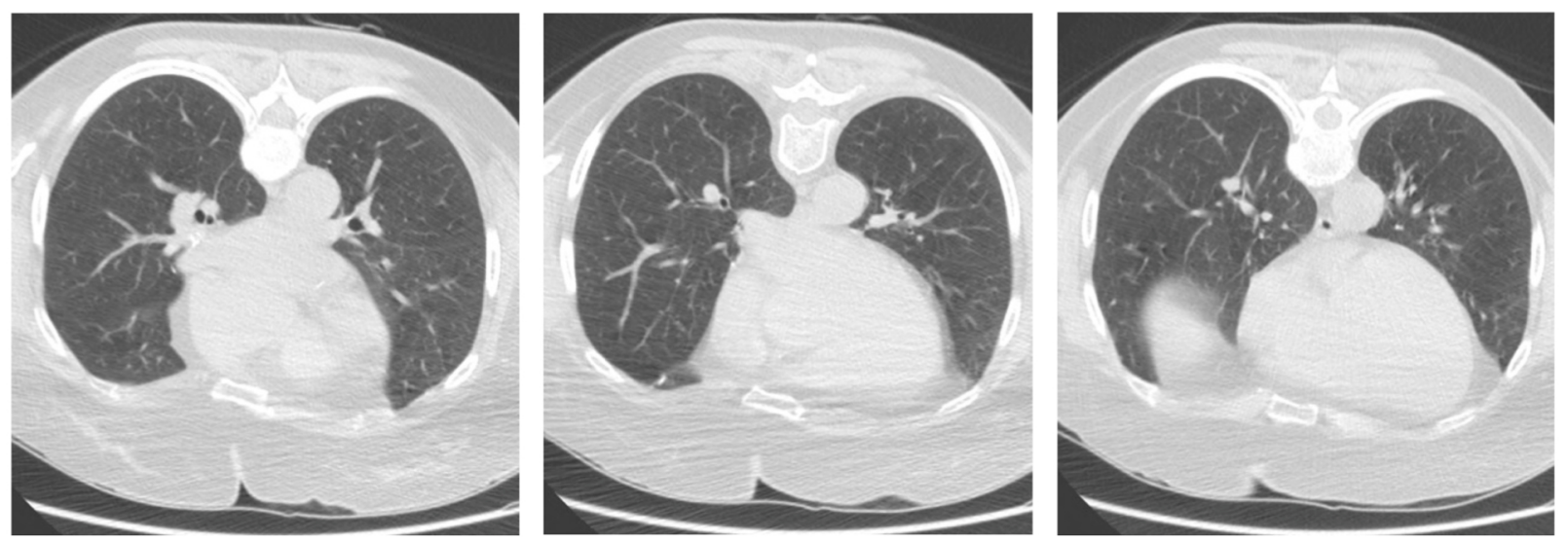

c.

Fig. 2. (a) 62-year-old woman with a left lower lobe nodule, biopsied in prone position. (b) Post-procedure CT scan control performed on the whole thorax shows a systemic air embolism in the left atrium (white arrow) and the left ventricle (black arrow). (c) CT scan control performed 4 min later shows a complete resorption of air. 
Results of univariate and multivariate analysis of risk factors of air embolism.

\begin{tabular}{|c|c|c|c|c|c|c|c|c|}
\hline \multirow[b]{3}{*}{ Age (for 5 years) } & \multicolumn{4}{|c|}{ Univariate analysis $^{\mathrm{a}}(\mathrm{N}=559)$} & \multicolumn{4}{|c|}{ Multivariate analysis $(\mathrm{N}=556)$} \\
\hline & $\mathrm{OR}_{\text {raw }}$ & $95 \% \mathrm{CI}_{\text {raw }}$ & & $\mathbf{P}_{\text {raw }}$ & OR $_{\text {adjust }}$ & $95 \% \mathrm{C}$ & & $\mathbf{P}_{\text {adjust }}$ \\
\hline & 1.03 & {$[0.99$} & 1.07] & 0.116 & 1.04 & {$[1.00$} & $1.08]$ & 0.062 \\
\hline Ipsilateral radiotherapy & 3.19 & {$[0.68$} & 14.93] & 0.14 & & & NS & \\
\hline Length of needle path through ventilated lung (for $5 \mathrm{~mm}$ ) & 1.10 & {$[0.99$} & $1.22]$ & 0.087 & 1.13 & {$[1.02$} & $1.25]$ & 0.024 \\
\hline Number of biopsy samples ( 1 unit) & 1.45 & {$[1.007$} & $2.076]$ & 0.046 & 1.48 & {$[1.01$} & $2.17]$ & 0.046 \\
\hline \multicolumn{9}{|l|}{ Number of pleural passes } \\
\hline$>1$ & 1.96 & {$[0.86$} & 4.49] & 0.110 & & NS & & \\
\hline 1 & 1 & & & & & & & \\
\hline Position & & & & 0.028 & & & & 0.013 \\
\hline Right lateral decubitus (RLD) & 5.35 & {$[1.49$} & 19.27] & 0.010 & 6.15 & {$[1.66$} & $22.85]$ & 0.005 \\
\hline Prone & 3.02 & {$[1.10$} & $8.31]$ & 0.033 & 3.12 & {$[1.11$} & $8.76]$ & 0.031 \\
\hline Other ${ }^{\mathrm{b}}$ & 1 & & & & 1 & & & \\
\hline Spirometry data & & & & 0.145 & & & & \\
\hline Obstructive pattern & 2.10 & {$[0.97$} & $4.70]$ & 0.072 & & NS & & \\
\hline Restrictive pattern & 2.66 & {$[0.56$} & $12.66]$ & 0.219 & & & & \\
\hline Normal & 1 & & & & & & & \\
\hline \multicolumn{9}{|l|}{ Emphysema } \\
\hline Yes & 1.19 & {$[0.55$} & 2.59] & 0.663 & & NS & & \\
\hline No & 1 & & & & & & & \\
\hline
\end{tabular}

a wald chi-2.

b Other $=$ supine or left lateral decubitus.

model because there were strongly correlated with length of needle path through ventilated lung.

Logistic regression results (Table 3) confirmed that the most important risk factors for air embolism were position $\left(\mathrm{OR}_{R L D^{*}}\right.$ vs. Other**:

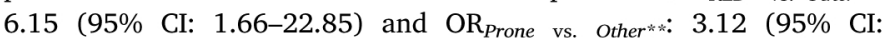
1.11-8.76)), length of needle path through ventilated lung and number of biopsy samples. Thus, for each additional biopsy sample or for each increase of $5 \mathrm{~mm}$ of the length, the probability of air embolism was multiplied by respectively 1.48 (95\% CI: $1.01-2.17)$ and 1.13 (95\% CI: 1.02-1.25). Age had also an important prognostic value with a multiplication of air embolism probability by a factor of 1.20 for each increase of five years (95\% CI: 0.99-1.46).

\subsection{Other complications}

Pneumothorax developed in 90 patients. Among them, 58 were treated with a chest tube (10.4\%) of whom 4 in "air embolism group" (14.8\%, p = 0.51).

Parenchymal hemorrhage was detected on CT in 171 patients $(30.6 \%)$ of whom 10 in "air embolism group" $(37 \%, \mathrm{p}=0.46)$. Hemoptysis occurred in 35 patients (6.3\%) within the global population, none in the "air embolism group" ( $p=0.17)$. All were self-limiting.

There were no significant differences in terms of associated complications between patients with or without post-biopsy air embolism.

\section{Discussion}

This study showed an almost 5\% systemic air embolism incidence after percutaneous lung biopsy, when a post procedural CT acquisition of the entire thorax is systematically performed. Prone and right lateral position, numerous biopsy samples and longer needle path length were independent risk factors for SAE in our study.

This incidence founded herein is significantly higher than expected. In most previous retrospective studies reporting less than $1 \% \mathrm{SAE}$ incidence, the control CT scan was either limited to the target area or the length of the CT acquisition was not specified. For example, a study led by Ibukuro [15], in which he clearly outlines the limitations used i.e. focusing on a target area and not on the entire chest, found a $0.21 \%$ incidence of SAE. Similarly, a retrospective study of 2216 patients led by Ishii [16] found an overall $0.45 \%$ SAE rate after biopsy, but there was no mention as to whether their analysis extended to the whole chest or focused on the target area. Conversely, in the study by Freund [13], who performed a whole thoracic CT acquisition, the reported incidence of SAE was 3.8\%, which is in phase with our results. For 21 of the 27 patients who presented SAE in our study (78\%), the nodule area did not correspond to the level of the cardiac cavities. By limiting the volume of the post procedure CT scan to the target area, our SAE rate would have been only $1 \%$ instead of $5 \%$. The radiation exposure increase related to the increase in acquisition volume must be weighed against the expected benefit of an early diagnosis of air embolism. The performance of an additional ultra-low dose acquisition could be evaluated in a further prospective study.

In order to reduce the number of pleural and intra-parenchymal passes, we always used a coaxial needle of $17 \mathrm{G}$ so this factor could not be analyzed. Furthermore, large pathological samples are needed for pathology diagnosis and fingerprint analysis regarding guideline recommendations. Theoretically, larger needle size could increase the risk of air embolism but it is noteworthy that many cases described in the literature have occurred with small needle and non-coaxial techniques $[5,7,17,18]$. In a large meta-analysis of Heerink [19], needle size was not a significant risk factor for major complications.

Identifying air bubbles in the cardiac cavities before their migration into the systemic arteries allows specific management to limit clinical complications. The non-mobilization of patients during the first minutes of oxygen therapy and the CT assessment of air disappearance before mobilization, may contribute to reduce air migration and systemic complications $[11,13,20]$. The fact that the only patient who developed symptoms in our study had prematurely moved, confirms the importance of these management measures.

Two main mechanisms are recognized as potential causes of air embolism during percutaneous lung biopsy. The first one is a direct communication between a pulmonary vein and the needle lumen when the coaxial needle stylet is removed. Occurrence of SAE depends on the gradient between air and pulmonary vein. Atmospheric pressure being constant, only a decrease in venous pressure can lead to air intake, especially during deep inspiration, which should absolutely be avoided during transition maneuvers. However, this implies that the tip of the needle is unintentionally misplaced in a pulmonary vein instead of being inside the target lesion. This is more likely to happen for small lesions, however the target lesion size was not found to be a risk factor for SAE in our study. Secondly, the needle path through aerated lung may create a fistula between the airways and the pulmonary veins. Then, any pressure increase in the airways may promote air embolism. 
This is the case when patients are coughing or present severe COPD and air trapping $[8,21,22]$. Unfortunately, we could not evaluate the importance of coughing because this parameter was not systematically reported. A higher frequency of airflow obstruction was observed in patients with SAE in our study, even though this was not significant. Some authors hypothesized that tumour location at a level higher than that of the left atrium, could promote the occurrence of SAE by increasing the gradient between airway and pulmonary vein pressure, especially in prone position [13]. They recommended to perform transthoracic biopsy with the patient in an ipsilateral-dependent position to prevent SAE [23]. We found a higher incidence of SAE in prone position but also in right lateral decubitus. This can be explained by an increased vertical gradient in blood flow in right lateral decubitus [24]. Nevertheless, the gradient theory is probably insufficient in itself. Other parameters are likely to increase the risk of fistula between the airways and the pulmonary veins, such as longer needle path length through ventilated lung or higher number of biopsy samples, both appearing as independent risk factors in our study.

Certain conditions such as post-inflammatory changes in a portion of the lung traversed by the needle, increase vascularity, vasculitis or friable lung tissue, can interfere with the normal hemostatic mechanisms and result in prolonged exposure of the vessel lumen to the airway $[8,18,25]$. We have only found a trend of higher risk in case of prior ipsilateral radiotherapy (7.4 versus $4.8 \%$ ) but this was not significant $(p=0.16)$ maybe because of the small number of irradiated patients. Similarly, we did not find any associated with vasculitis, but this again might be explained by the limited number of cases.

In a recent retrospective study of 1014 patients, of which half had post biopsy CT scan performed on the entire thorax Jang H et Al [26] identified location of the needle tip outside of the lesion and pulmonary hemorrhage as significant risk factors for SAE. These two parameters were not associated with an increased risk of SAE in our study. Patient positioning was not associated with the occurrence of SAE in the study by Jang et al but they used different definitions, with a distinction between prone and oblique prone position which could partly explain our different results.

\subsection{Limitations}

Our study had several limitations. First, the design was retrospective. Therefore, some risk factors such as coughing could not be assessed because they were not systematically reported. Second, even if the sample size was relatively high, it did not allow to reach statistically significance for infrequent risk factors. Third, it was a monocentric study. However, the procedures used correspond to standard practice.

The last limitation concerns the lack of proof that early management in asymptomatic SAE patients significantly decreases the complication rate. This would require a randomized study which is not possible to undertake in view of the rarity of SAE. Furthermore, it would not be ethical to not apply preventive measures in one SAE patient group.

In conclusion, we showed that post lung biopsy systemic air embolism is a more frequent complication than expected, when performing whole thoracic CT acquisition, with a radiological incidence of $4.8 \%$. A control CT scan of the whole thorax should thus systematically be performed after lung biopsy, before patient mobilization with particular attention to detect the slightest presence of air in the left cardiac cavities or aorta, in order to prevent systemic complications by adapted management. Several factors are likely to favor the occurrence of SAE such as prone and right lateral position, higher number of biopsy samples and longer needle path length through ventilated lung. Being aware of these risk factors could contribute to reduce SAE incidence, the most severe complication of percutaneous lung biopsy.

\section{Author declaration}

We wish to confirm that there are no known conflicts of interest associated with this publication and there has been no significant financial support for this work that could have influenced its outcome.

We confirm that the manuscript has been read and approved by all named authors and that there are no other persons who satisfied the criteria for authorship but are not listed. We further confirm that the order of authors listed in the manuscript has been approved by all of us.

We confirm that we have given due consideration to the protection of intellectual property associated with this work and that there are no impediments to publication, including the timing of publication, with respect to intellectual property. In so doing we confirm that we have followed the regulations of our institutions concerning intellectual property.

\section{References}

[1] C.M. Richardson, K.S. Pointon, A.R. Manhire, J.T. Macfarlane, Percutaneous lung biopsies: a survey of UK practice based on 5444 biopsies, Br. J. Radiol. 75 (897) (2002) 731-735.

[2] N. Tomiyama, Y. Yasuhara, Y. Nakajima, S. Adachi, Y. Arai, M. Kusumoto, K. Eguchi, K. Kuriyama, F. Sakai, M. Noguchi, K. Murata, S. Murayama, T. Mochizuki, K. Mori, K. Yamada, CT-guided needle biopsy of lung lesions: a survey of severe complication based on 9783 biopsies in Japan, Eur. J. Radiol. 59 (1) (2006) 60-64.

[3] K.M. Shin, J.K. Lim, C.H. Kim, Delayed presentation of cerebellar and spinal cord infarction as a complication of computed tomography-guided transthoracic lung biopsy: a case report, J. Med. Case Rep. 8272.

[4] B. Mokhlesi, I. Ansaarie, M. Bader, M. Tareen, J. Boatman, Coronary artery air embolism complicating a CT-guided transthoracic needle biopsy of the lung, Chest 121 (3) (2002) 993-996.

[5] A. Mansour, S. AbdelRaouf, M. Qandeel, M. Swaidan, Acute coronary artery air embolism following CT-guided lung biopsy, Cardiovasc. Intervent. Radiol. 28 (1) (2005) 131-134.

[6] S. Hirasawa, H. Hirasawa, A. Taketomi-Takahashi, H. Morita, Y. Tsushima, M. Amanuma, K. Endo, Air embolism detected during computed tomography fluoroscopically guided transthoracic needle biopsy, Cardiovasc. Intervent. Radiol. 31 (1) (2008) 219-221.

[7] T. Hiraki, H. Fujiwara, J. Sakurai, T. Iguchi, H. Gobara, N. Tajiri, H. Mimura, S. Kanazawa, Nonfatal systemic air embolism complicating percutaneous CT-guided transthoracic needle biopsy: four cases from a single institution, Chest 132 (2) (2007) 684-690.

[8] B.W. Arnold, W.J. Zwiebel, Percutaneous transthoracic needle biopsy complicated by air embolism, AJR Am. J. Roentgenol. 178 (6) (2002) 1400-1402.

[9] K. Ashizawa, H. Watanabe, H. Morooka, K. Hayashi, Hyperbaric oxygen therapy for air embolism complicating CT-guided needle biopsy of the lung, AJR Am. J. Roentgenol. 182 (6) (2004) 1606-1607.

[10] A. Singh, A. Ramanakumar, J. Hannan, Simultaneous left ventricular and cerebral artery air embolism after computed tomographic-guided transthoracic needle biopsy of the lung, Tex. Heart Inst. J. 38 (4) (2011) 424-426.

[11] G. Rott, F. Boecker, Influenceable and avoidable risk factors for systemic air embolism due to percutaneous CT-Guided lung biopsy: patient positioning and coaxial biopsy technique-case report, systematic literature review, and a technical note, Radiol. Res. Pract. 2014 (2014) 349062.

[12] H.K. Kok, S. Leong, U. Salati, W.C. Torreggiani, P. Govender, Left atrial and systemic air embolism after lung biopsy: importance of treatment positioning, J. Vasc. Interv. Radiol. 24 (10) (2013) 1587-1588.

[13] M.C. Freund, J. Petersen, K.C. Goder, T. Bunse, F. Wiedermann, B. Glodny, Systemic air embolism during percutaneous core needle biopsy of the lung: frequency and risk factors, BMC Pulm. Med. 12 (2012) 2.

[14] I.C. Tsai, W.L. Tsai, M.C. Chen, G.C. Chang, W.S. Tzeng, S.W. Chan, C.C. Chen, CT guided core biopsy of lung lesions: a primer, AJR Am. J. Roentgenol. 193 (5) (2009) 1228-1235.

[15] K. Ibukuro, R. Tanaka, T. Takeguchi, H. Fukuda, S. Abe, K. Tobe, Air embolism and needle track implantation complicating CT-guided percutaneous thoracic biopsy: single-institution experience, AJR Am. J. Roentgenol. 193 (5) (2009) W430-W436.

[16] H. Ishii, T. Hiraki, H. Gobara, H. Fujiwara, H. Mimura, K. Yasui, T. Doke, T. Mukai, H. Kurokawa, Y. Ando, S. Hase, T. Iguchi, T. Yabuki, K. Omae, N. Tajiri, T. Mitsuhashi, S. Kanazawa, Risk factors for systemic air embolism as a complication of percutaneous CT-guided lung biopsy: multicenter case-control study, Cardiovasc. Intervent. Radiol. 37 (5) (2014) 1312-1320.

[17] S.J. Um, S.K. Lee, D.K. Yang, C. Son, K.N. Kim, K.N. Lee, Y.S. Kim, Four cases of a cerebral air embolism complicating a percutaneous transthoracic needle biopsy, Korean J. Radiol. 10 (1) (2009) 81-84.

[18] S.S. Hare, A. Gupta, A.T. Goncalves, C.A. Souza, F. Matzinger, J.M. Seely, Systemic arterial air embolism after percutaneous lung biopsy, Clin. Radiol. 66(7) 589-596.

[19] W.J. Heerink, G.H. de Bock, G.J. de Jonge, H.J. Groen, R. Vliegenthart, M. Oudkerk, Complication rates of CT-guided transthoracic lung biopsy: meta-analysis, Eur. Radiol. 27 (1) (2017) 138-148.

[20] A. Khalil, H. Prigent, A. Parrot, M.F. Carette, Systemic air embolism complicating percutaneous transthoracic needle biopsy, AJR Am. J. Roentgenol. 187 (2) (2006) W242-W243.

[21] W.M. Al-Ali, T. Browne, R. Jones, A case of cranial air embolism after transthoracic lung biopsy, Am. J. Respir. Crit. Care Med. 186(11) 1193-1195. 
[22] W. Bou-Assaly, P. Pernicano, E. Hoeffner, Systemic air embolism after transthoracic lung biopsy: A case report and review of literature, World J. Radiol. 2(5) 193-196.

[23] B. Glodny, E. Schonherr, M.C. Freund, M. Haslauer, J. Petersen, A. Loizides, A.E. Grams, F. Augustin, F.J. Wiedermann, R. Rehwald, Measures to prevent air embolism in transthoracic biopsy of the lung, AJR Am. J. Roentgenol. 208 (5) (2017) W184-W191.

[24] H. Chang, S.J. Lai-Fook, K.B. Domino, C. Schimmel, J. Hildebrandt, H.T. Robertson,
R.W. Glenny, M.P. Hlastala, Spatial distribution of ventilation and perfusion in anesthetized dogs in lateral postures, J. Appl. Physiol. 92 (2) (1985) 745-762 2002.

[25] M. Ghafoori, P. Varedi, Systemic air embolism after percutaneous transthorasic needle biopsy of the lung, Emerg. Radiol. 15 (5) (2008) 353-356.

[26] H. Jang, J.Y. Rho, Y.J. Suh, Y.J. Jeong, Asymptomatic systemic air embolism after CT-guided percutaneous transthoracic needle biopsy, Clin. Imaging 53 (2019) $49-57$. 